\title{
The Initial Stage Corrosion of X80 Steel in Saturated Sandy Soil Containing $\mathrm{Cl}^{-}$and $\mathrm{SO}_{4}{ }^{2-}$
}

\author{
Funan Sun ${ }^{1}$, Ruizhen Xie ${ }^{2}$, Bin He ${ }^{1}$, Zhiwei Chen ${ }^{1}$, Xiangling Bai ${ }^{1}$, Pengju Han ${ }^{1 *}$ \\ ${ }^{1}$ College of Civil Engineering, Taiyuan University of Technology, Taiyuan, 030024, China \\ ${ }^{2}$ Mechanics Institute, Jinzhong University, Jinzhong, 030619, China \\ "E-mail: $13834569544 @ 163 . c o m$
}

doi: $10.20964 / 2021.01 .01$

Received: 28 August 2020 / Accepted: 18 October 2020 / Published: 30 November 2020

The corrosion differences of X80 steel are exhibited by electrochemical impedance spectroscopy, polarization curves, and scanning electron microscopy in saturated sandy soil containing different concentrations of $\mathrm{NaCl}$ and $\mathrm{Na}_{2} \mathrm{SO}_{4}$ under indoor simulation conditions. The corrosion rate of X80 steel is minimal with $\mathrm{NaCl}$ and $\mathrm{Na}_{2} \mathrm{SO}_{4}$ concentrations of $0.5 \%$ and $0.3 \%$, respectively. Additionally, the corrosion morphologies are mainly shallow and small pits. However, the corrosion rates are hindered due to the accumulation of oxide films on the surface of X80 steel. The increase in sodium salt content accelerates the overall corrosion rate until 1.0\%. Meantime, the oxide films are eroded by $\mathrm{Cl}^{-}$and $\mathrm{SO}_{4}{ }^{2-}$ and re-accelerate the electrochemical corrosion process, so the pits evidently deepen and expand.

Keywords: X80 steel, saturated soil, corrosion, polarization curves, EIS

\section{FULL TEXT}

(C) 2021 The Authors. Published by ESG (www.electrochemsci.org). This article is an open access article distributed under the terms and conditions of the Creative Commons Attribution license (http://creativecommons.org/licenses/by/4.0/). 